\title{
Vaccines adjuvanted with an NKT cell agonist induce effective T-cell responses in models of CNS lymphoma
}

\author{
Carole Grasso*,‡,1(iD), Cameron S Field ${ }^{\ddagger}{ }^{1}$, Ching-Wen Tang ${ }^{1,2}$, Peter M Ferguson ${ }^{3}$, Benjamin \\ J Compton ${ }^{4}$, Regan J Anderson ${ }^{4}$, Gavin F Painter ${ }^{4}$, Robert Weinkove ${ }^{1,5,6}$, Ian F Hermans ${ }^{1,2}$ \\ \& Michael V Berridge ${ }^{1}$ \\ ${ }^{1}$ Malaghan Institute of Medical Research, P.O. Box 7060, Wellington 6242, New Zealand \\ ${ }^{2}$ Maurice Wilkins Centre for Molecular Biodiscovery, Private Bag 92019, Auckland 1042, New Zealand \\ ${ }^{3}$ Melanoma Institute Australia, 40 Rocklands Road, Wollstonecraft, NSW 2065, Australia \\ ${ }^{4}$ The Ferrier Research Institute, Victoria University of Wellington, P.O. Box 33436, Lower Hutt 5046, New Zealand \\ ${ }^{5}$ Wellington Blood \& Cancer Centre, Capital \& Coast District Health Board, P.O. Box 7902, Wellington 6242, New Zealand \\ ${ }^{6}$ Department of Pathology \& Molecular Medicine, University of Otago Wellington, P.O. Box 7343, Wellington 6242, New Zealand \\ *Author for correspondence: cgrasso@malaghan.org.nz \\ $\ddagger$ Authors contributed equally
}

\begin{abstract}
Aim: The efficacy of anti-lymphoma vaccines that exploit the cellular adjuvant properties of activated natural killer T (NKT) cells were examined in mouse models of CNS lymphoma. Materials \& methods: Vaccines were prepared by either loading the NKT cell agonist, $\alpha$-galactosylceramide onto irradiated and heatshocked B- and T-lymphoma cells, or chemically conjugating $\alpha$-galactosylceramide to MHC-binding peptides from a lymphoma-associated antigen. Vaccine efficacy was analyzed in mice bearing intracranial tumors. Results: Both forms of vaccine proved to be effective in preventing lymphoma engraftment through activity of T cells that accessed the CNS. Established lymphoma was harder to treat with responses constrained by Tregs, but this could be overcome by depleting Tregs prior to vaccination. Conclusion: Simply designed NKT cell-activating vaccines enhance T-cell responses and have the potential to protect against CNS lymphoma development or prevent CNS relapse. To be effective against established CNS lymphoma, vaccines need to be combined with Treg suppression.
\end{abstract}

First draft submitted: 5 August 2019; Accepted for publication: 2 April 2020; Published online:

22 April 2020

Keywords: $\alpha$-galactosylceramide $\bullet$ CNS $\bullet$ immunotherapy $\bullet$ lymphoma $\bullet$ NKT

The prognosis of aggressive lymphomas has improved with the widespread adoption of chemoimmunotherapy. However, primary CNS lymphoma and CNS relapses of systemic lymphomas carry a poor prognosis, in part due to the inability of many agents to cross the blood-brain barrier. Chemotherapies, kinase inhibitors and cranial irradiation are commonly employed, but these have significant toxicities and are rarely curative $[1,2]$. Immunotherapies have the potential to overcome these issues, with cancer vaccines an attractive concept due to limited adverse effects and the capacity for $T$ cells to penetrate the blood-brain barrier [3]. However, clinical responses to existing vaccines have been disappointing in systemic lymphoma and the immunosuppressive microenvironment of CNS lymphoma must be overcome $[4,5]$. New approaches to vaccine design are required to generate immune responses of sufficient quality and quantity for clinical relevance.

Vaccine-induced antitumor T-cell responses require processing of tumor-associated antigens (TAAs) by antigenpresenting cells (APCs), and TAA presentation to T cells via MHC molecules on the APC surface. Importantly, APCs must be activated to induce strong T-cell proliferation and differentiation. This can be achieved through interaction with third party cells, such as natural killer T (NKT) cells, which can serve as 'cellular adjuvants' [6]. This activity is largely mediated by CD40 ligation $[7,8]$, leading to enhanced costimulatory molecule expression on APCs and promoting release of proinflammatory cytokines. Glycolipids that bind to the MHC-like molecule CD1d on APCs, and serve as agonists of NKT cells, such as $\alpha$-galactosylceramide ( $\alpha$-GalCer) [9], can therefore 
be included in vaccines to enhance responses $[10,11]$. This strategy has been shown to strengthen T-cell responses against TAA-derived peptides that are co-presented by the same APC, and enhance anti-tumor activity in animal models $[12,13]$.

Simple cellular vaccines based on whole tumor cells loaded with $\alpha$-GalCer, which is acquired and presented by resident APCs, have proven effective as cancer vaccines in models of glioblastoma and systemic lymphoma [14,15]. Strategies to conjugate synthetic antigens to $\alpha$-GalCer, enabling co-delivery to resident APCs [16,17], have provided an opportunity to develop wholly synthetic vaccines as off-the-shelf therapies [18,19]. Importantly, as the CD1d molecule is nonpolymorphic and the T-cell receptor of NKT cells is largely invariant, the licensing capacity of NKT cells is conserved irrespective of tissue type, making $\alpha$-GalCer an appealing immune adjuvant. The flexibility of such a synthetic manufacturing process could also provide a platform for precision medicines against patient-specific TAAs.

Vaccines that exploit NKT cell activity can induce immune responses against systemic lymphomas in vivo [15,20], but their activity against CNS lymphoma has not been reported previously. Here, we used both cellular and synthetic $\alpha$-GalCer-adjuvanted vaccines to prevent and treat T- and B-cell lymphomas in the CNS in vivo.

\section{Materials \& methods \\ Mice}

Inbred C57BL/6 mice (for EL4 and EG.7-OVA study) or BALB/c ByJ mice (for A20 study) were purchased from Jackson Laboratories, Bar Harbour, Maine, and maintained by the Biomedical Research Unit at the Malaghan Institute of Medical Research. Mice were 6-12 weeks of age and matched for age and gender. All experiments were approved by the Victoria University Animal Ethics Committee and performed according to institutional guidelines.

\section{Cell lines \& reagents}

All reagents were purchased from Life Technologies, Wellington, New Zealand, except where stated otherwise. The murine B- (A20) and T-lymphoma (EL4) cell lines were cultured in RPMI, supplemented with 10\% fetal bovine serum (FBS; Sigma-Aldrich, USA), $100 \mathrm{U} / \mathrm{ml}$ penicillin and $100 \mu \mathrm{g} / \mathrm{ml}$ streptomycin, and $5 \%$ glutamax. EG.7-OVA cells (EL4 transfected with chicken ovalbumin [OVA] and neomycin resistance genes) were cultured in Iscove's Modified Dulbecco's Medium (IMDM), supplemented with 5\% FBS, penicillin and streptomycin, plus $500 \mu \mathrm{g} / \mathrm{ml}$ geneticin.

\section{Tumor implantation}

Mice were anesthetized by intraperitoneal injection of $100 \mathrm{mg} / \mathrm{kg}$ ketamine and $10 \mathrm{mg} / \mathrm{kg}$ xylazine, and lacrilube (Allergan, NJ, USA) was applied to the cornea to prevent desiccation. Subcutaneous injection of $5 \mathrm{mg} / \mathrm{kg}$ carprofen (Norbrook Laboratories, Corby, UK) and $0.1 \mathrm{mg} / \mathrm{kg}$ buprenorphine (Renckitt Benckiser Pharmaceuticals, MO, USA) was used as a perioperative analgesic. A total of $5 \times 10^{3}$ EL4, EG.7-OVA or A20 cells in $2 \mu \mathrm{l}$ of phosphatebuffered saline (PBS) was injected using a 32-gauge needle into the right striatum, positioned 2.1-mm lateral from the bregma at a depth of $3 \mathrm{~mm}$, using a stereotactic frame (Stoelting, IL, USA). Time to appearance of symptoms was defined as time to $10 \%$ loss of weight or overt behavioral symptoms, such as hunching or reduced activity. The presence of tumors was confirmed by light microscopy on $3 \mu \mathrm{m}$ coronal sections from $10 \%$ formalin-fixed brains stained with hematoxylin and eosin.

\section{Vaccine generation \& administration}

To prepare cellular vaccines, $\alpha$-GalCer was manufactured as previously described [21], and solubilized by freezedrying the samples in the presence of sucrose, L-histidine and Tween 20, as previously described [22]. Cultures of EL4 or A20 cells in complete RPMI were supplemented with $200 \mathrm{ng} / \mathrm{ml} \alpha-$ GalCer for $24 \mathrm{~h}$ at $37^{\circ} \mathrm{C}$ in $5 \% \mathrm{CO}_{2}$ before being harvested and heat-shocked by immersion in a $43^{\circ} \mathrm{C}$ water bath for $50 \mathrm{~min}$ to increase immunogenicity and irradiated with $150 \mathrm{cGy}$ to prevent cell proliferation following tumor challenge [23]. Mice received one dose of vaccine consisting of $1 \times 10^{5}$ cells in $200 \mu \mathrm{PBS}$, injected intravenously, at times indicated in figure legends.

A synthetic vaccine comprising an $\alpha$-GalCer prodrug linked to a chicken OVA-derived peptide ( $\alpha$-GalCer$\mathrm{OVA}^{\mathrm{CD} 4 / \mathrm{CD} 8}$ ) was prepared by a modified literature procedure (see Supplementary Information) [24] to assess responses against lymphoma cells expressing OVA as a model TAA (EG.7-OVA). The peptide consisted of a tandem fusion of an $\mathrm{H}-2 \mathrm{~K}^{\mathrm{b}}$-binding $\mathrm{CD} 8^{+}$T-cell epitope $\left(\mathrm{OVA}_{257-264}\right.$, SIINFEKL), and H-2 I-A $\mathrm{A}^{\mathrm{b}}$-binding CD $4^{+}$ T-cell epitope (OVA ${ }_{323-339}$, ISQAVHAAHAEINEAGR), of OVA protein, with flanking sequences to aid cleavage, 
as previously described [24]. To assess the antilymphoma role of $\mathrm{CD} 4^{+} \mathrm{T}$ cells induced by vaccination, a second conjugate $\left(\alpha\right.$-GalCer-OVA $\left.{ }^{\mathrm{CD} 4 \mathrm{scr} / \mathrm{CD} 8}\right)$ was prepared with the $\mathrm{CD}^{+}{ }^{+}$-cell epitope fused to an altered version of the $\mathrm{CD}^{+}{ }^{+}$T-cell epitope (ISQAVHAAAAAINEAGR). The conjugate vaccines were solubilized in the same way as $\alpha$-GalCer, and for injection, were diluted in PBS to give a 0.052-nmol dose per mouse, injected intravenously. For prophylactic studies, mice were vaccinated with the synthetic vaccine 7 days before EG.7-OVA challenge. For therapeutic studies, mice were vaccinated 6 days after challenge.

\section{Antibody-mediated Treg depletion \& T-cell depletion}

For all experiments involving depletion of Tregs, mice were intraperitoneally administered with one dose of $125 \mu \mathrm{g}$ of affinity-purified $\alpha$-CD25 prepared in-house from the supernatant of clone PC61, at times indicated in figure

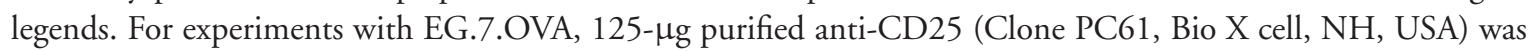
administered.

The depletion of $\mathrm{CD}^{+} \mathrm{T}$ cells was achieved by intraperitoneal injection of $\alpha$-CD4 antibody (clone GK1.5), and $\mathrm{CD}^{+}{ }^{+} \mathrm{T}$-cell depletion was achieved using $\alpha$-CD8 antibody (clone 2.43). Antibodies were injected 3 days prior to intracranial implantation $(0.5 \mathrm{mg}$ per mouse per dose), and then every 3 days until the end of the experiment.

\section{Cell preparation for flow cytometry}

For analysis of circulating $\mathrm{OVA}_{257-264}$-specific $\mathrm{CD}^{+} \mathrm{T}$ cells, blood was collected and erythrocytes lysed (RBC Lysis Solution, Qiagen) for $30 \mathrm{~min}$ at $37^{\circ} \mathrm{C}$ prior to flow cytometry. For analysis of immune infiltrates into the brain, whole brain tissue was collected and digested in incomplete IMDM supplemented with $4 \mu \mathrm{g} / \mathrm{ml} \mathrm{DNase} \mathrm{I}$ (Roche Diagnostics) and $2.4 \mathrm{mg} / \mathrm{ml}$ collagenase II (Gibco, Life Technologies) for $30 \mathrm{~min}$ at $37^{\circ} \mathrm{C}$. Digested tissue was pressed through an $18 \mathrm{G}$ needle and filtered with a $70-\mu \mathrm{m}$ cell strainer to prepare a single-cell suspension, which was centrifuged on a 37\% percoll gradient (GE Healthcare) at $760 \mathrm{~g}$ for $30 \mathrm{~min}$. Cells were recovered from the bottom of the gradient. Erythrocytes were lysed and cells washed in PBS supplemented with 1\% FBS, 2 mM EDTA and $0.01 \%$ sodium azide.

\section{Flow cytometry}

Blood or brain single-cell suspensions were washed in PBS supplemented with 1\% FBS, 2 mM EDTA and 0.01\% sodium azide, and incubated for $10 \mathrm{~min}$ at $4^{\circ} \mathrm{C}$ with culture supernatant from the hybridoma cell line $2.4 \mathrm{G} 2$ to block Fc receptors. The cells were surface stained with fluorochrome-conjugated monoclonal antibody for 15 min at $4^{\circ} \mathrm{C}$. LIVE/DEAD fixable blue dye (Life Technologies) was used to exclude dead cells. The following antibodies were used: anti-CD45.1 (clone A20, BioLegend), anti-CD11b (clone M1/70, BD), anti-CD19 (clone 6D5, BioLegend), anti-CD3 (clone 145-2C11, BioLegend), anti-CD4 (clone RM4-5, BD), anti-CD8 (clone 53-6.7, BD or Biolegend), anti-FOXP3 (clone FJK-16s, eBioscience), anti-CD44 (clone IM7, BioLegend), antiCD62L (clone MEL-14, BD), anti-CD127 (clone A7R34, BioLegend) and anti-KLRG1 (clone 2F1, eBioscience). OVA-specific $\mathrm{CD}^{+} \mathrm{T}$ cells were detected using $\mathrm{H}-2 \mathrm{~K}^{\mathrm{b}} /$ SIINFEKL pentamers (ProImmune). Intracellular FoxP3 staining was performed using BioLegend FOXP3 Fix/Perm Buffer Set. Samples were acquired on LSRII Flow Cytometer (BD), and the data were analyzed using FlowJo software (TreeStar Inc.).

\section{Statistical analysis}

The Log-rank (Mantel-Cox) Test was used to determine statistical significance between Kaplan-Meier survival curves (Prism 5.0 software, GraphPad Software, Inc.). p-values of $<0.05$ considered significant $\left({ }^{*} \mathrm{p}<0.05 ;{ }^{* *} \mathrm{p}<\right.$ $\left.0.01{ }^{* * *} \mathrm{p}<0.001 ;{ }^{* * * *} \mathrm{p}<0.0001\right)$. Unpaired $t$-test was used for pentamer-staining analysis. $\mathrm{p}$-values for flow cytometry were calculated from one-way ANOVA. ${ }^{*} \mathrm{p}<0.05,{ }^{* *} \mathrm{p}<0.005,{ }^{* * *} \mathrm{p}<0.0005$.

To calculate the fold-change of immune-infiltrating cells into the brain, absolute counts were used. All live brain cells were counted using a hemocytometer (after red blood cell lysis), and immune cell component determined based on flow cytometry with antibody to CD45.1. The frequency of each immune cell type in the infiltrate was established by flow cytometry, and absolute number then determined. Fold-change for each cell-type was calculated using counts for each animal in each group, expressed as fold-change over mean number of cells in the untreated (PBS) group. 


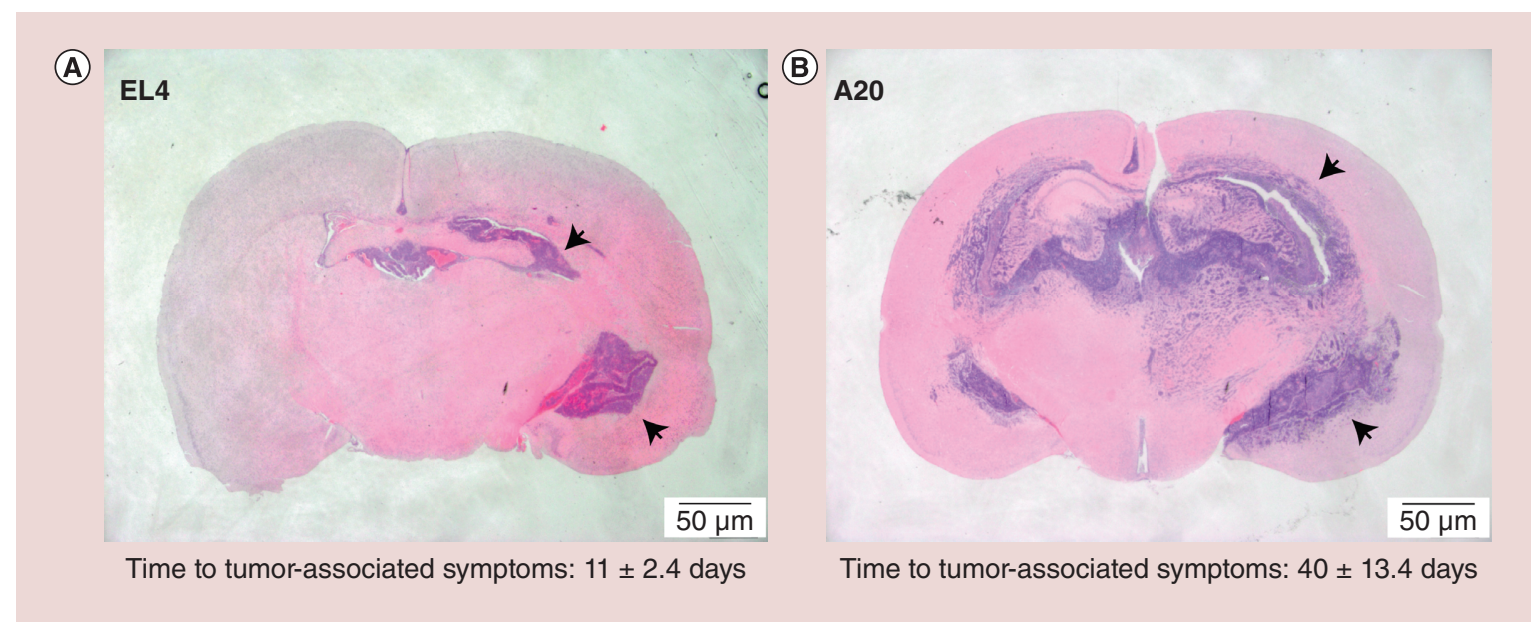

Figure 1. EL4 and A20 lymphoma growth in the brain. (A) Photomicrographs of hematoxylin and eosin stained coronal sections from mice bearing intracranial EL4 tumor and (B) A20 tumor. Tumors indicated by arrows.

\section{Results}

Intracranial implantation of EL4 \& A20 cell lines as models of CNS lymphomas

Intracranial implantation of the T lymphoblast cell line EL4 into mice led to CNS symptoms after $11 \pm 2.4$ (mean $\pm \mathrm{SD}$ ) days. Histologically, engrafted cells displayed a diffuse growth pattern, forming solid masses in the neural parenchyma and leptomeninges, with an infiltrating border and extension into the ependymal-lined ventricular spaces (Figure 1A). Intracranial implantation of the B-cell lymphoma line A20 led to similar symptoms after $40 \pm 13.4$ days. Engrafted cells formed dense aggregates with infiltrating borders around ependymal-lined ventricular spaces, with cells focused on cuffs around vascular structures in neural tissue, leptomeninges and choroid plexus, eliciting a gliotic response (Figure 1B).

Cellular vaccines adjuvanted with $\alpha$-GalCer provide protection against CNS lymphoma development but require combination with Treg depletion for efficacy

Whole tumor cell vaccines are effective in animal models of systemic lymphoma [15,20], and in clinical trials exhibit immunologic efficacy in lymphoid malignancies $[25,26]$. Here, we showed that prophylactic vaccination with $\alpha$-GalCer-adjuvanted cellular vaccines prevented or delayed development of both T- (EL4) and B-cell (A20) lymphomas in the CNS (Figure 2A). Protection involved activation of NKT cells, as indicated by increased cell number in spleen, with downregulation of NK1.1 on the cell surface (Supplementary Data Figure 1). Cellular vaccines without the NKT cell agonist did not provide protection in either model. The tumor material was required, as free $\alpha$-GalCer alone also failed to confer protection.

In contrast to the prophylactic setting, administration of $\alpha$-GalCer-adjuvanted cellular vaccines to mice with established, but asymptomatic, CNS lymphoma conferred no survival advantage (Figure 2B). Primary CNS lymphomas contain tumor-infiltrating T cells expressing the Treg-associated marker Foxp3 [5]. Therefore, we combined therapeutic vaccination with Treg depletion. Administration of $\alpha-C D 25$ monoclonal antibody successfully depleted Tregs in spleen and blood ( $\sim 98 \%$ reduction $\mathrm{CD}^{+} \mathrm{CD} 25^{+} \mathrm{T}$ cells; Supplementary Data Figure 2$)$. Depletion of Tregs alone did not delay progression of CNS lymphoma, but when conducted before therapeutic vaccination, survival was improved (Figure 2B).

Cellular vaccine activity against CNS lymphoma involves both $\mathrm{CD} 4^{+} \& \mathrm{CD} 8^{+} \mathrm{T}$ cells

In vivo models of NKT cell-activating vaccines against systemic lymphoma have indicated both $\mathrm{CD} 4^{+} \mathrm{T}$-cell dependent [27] and $\mathrm{CD}^{+}$T-cell dependent [15] mechanisms. Here, depletion of either $\mathrm{CD}^{+}{ }^{+}$or $\mathrm{CD}^{+}$cells abrogated efficacy of the cellular vaccine against CNS lymphoma, suggesting both populations are involved in vaccine-induced protection (Figure 3). 
(A)
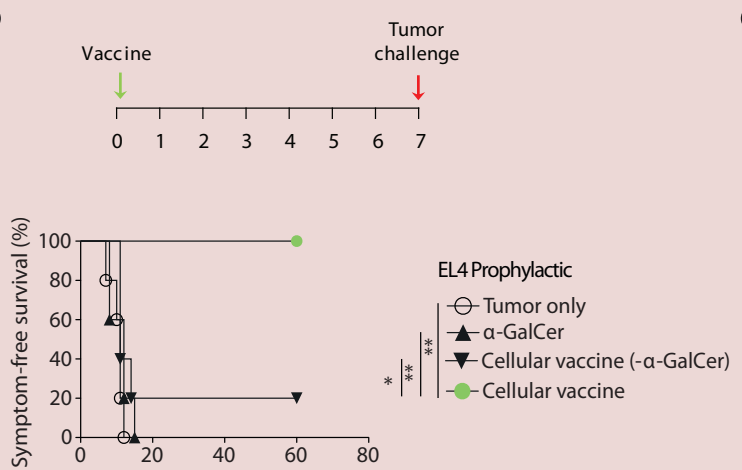

Days post intra-cranial challenge

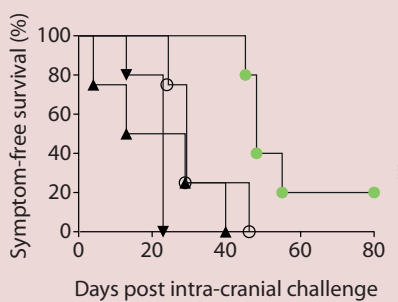

A20 Prophylactic

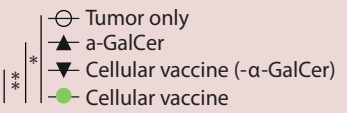

O Tumor only

$|*| \begin{aligned} & \boldsymbol{\nabla} \text { Cellular vaccin } \\ & -\mathrm{-}-\text { Cellular vaccin }\end{aligned}$
(B)

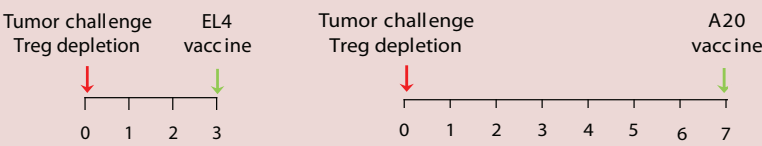

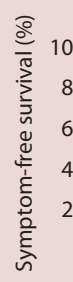

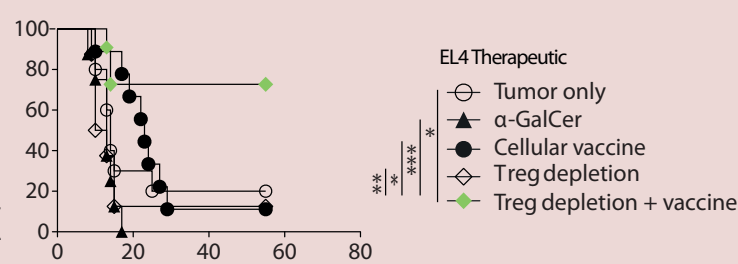

Days post intra-cranial challenge

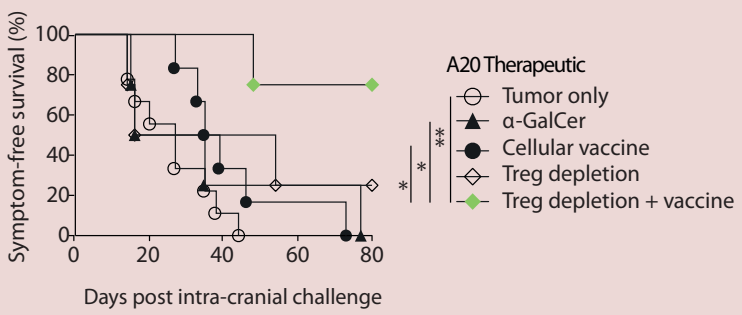

Figure 2. Treatment of intracranial EL4 and A20 lymphoma with $\alpha$-galactosylceramide cellular vaccine and Treg depletion protects against CNS lymphoma. (A) Symptom-free survival curves for mice ( $n=5 /$ group) vaccinated 7 days before EL4 or A20 intracranial challenge with either free $\alpha$-GalCer, heat-shocked and irradiated cells (cellular vaccine - $\alpha$-GalCer), or heat-shocked and irradiated cells loaded with $\alpha$-GalCer (cellular vaccine). Results representative of two independent experiments. (B) Mice challenged with intracranial EL4 cells ( $n=8-11 /$ group) or A20 cells ( $n=5 /$ group), followed by vaccination with either free $\alpha$-GalCer, cellular vaccine, Treg depletion or combination treatment. For EL4 and A20 studies, Treg depletion was on the day of intracranial injection; vaccine was administered after 3 days for EL4, and after 7 days for A20. Results of two combined experiments for EL4, and representative of two independent experiments for A20. * $p<0.05 ; * * p<0.01 ; * * * p 0.001$. $\alpha$-GalCer: $\alpha$-Galactosylceramide.

(A)

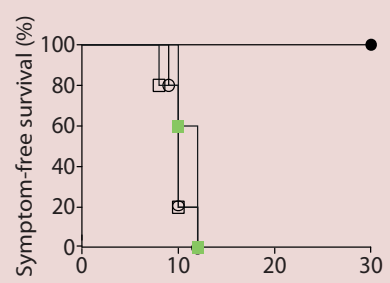

Days post intra-cranial challenge
(B)

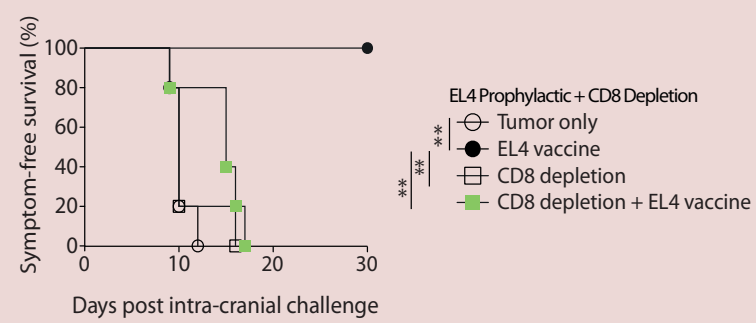

Figure 3. Protection against CNS lymphoma is mediated by $\mathrm{CD}^{+}$and $\mathrm{CD} 8^{+} \mathrm{T}$ cells. (A) Symptom-free survival curves for mice treated with CD4-depleting antibodies and cellular vaccine 7 days before EL4 intracranial challenge. (B) Experiment repeated using CD8-depleting antibodies. Results representative of two independent experiments ( $n=5 /$ group). ${ }^{* *} \mathrm{p}<0.01$.

\section{A synthetic vaccine comprising antigenic peptide conjugated to an $\alpha$-GalCer prodrug provides}

\section{protection against CNS lymphoma}

Clinical application of autologous tumor cell vaccines may be limited by logistical challenges and cost [28]. To overcome this, we employed a fully synthetic vaccine $\left(\alpha-\right.$ GalCer-OVA $\left.{ }^{\mathrm{CD}} 4 / \mathrm{CD} 8\right)$ incorporating an $\alpha$-GalCer prodrug linked to OVA-derived $\mathrm{CD}^{+}$and $\mathrm{CD}^{+}$T-cell peptide epitopes (Figure 4). Designed to codeliver antigenic 


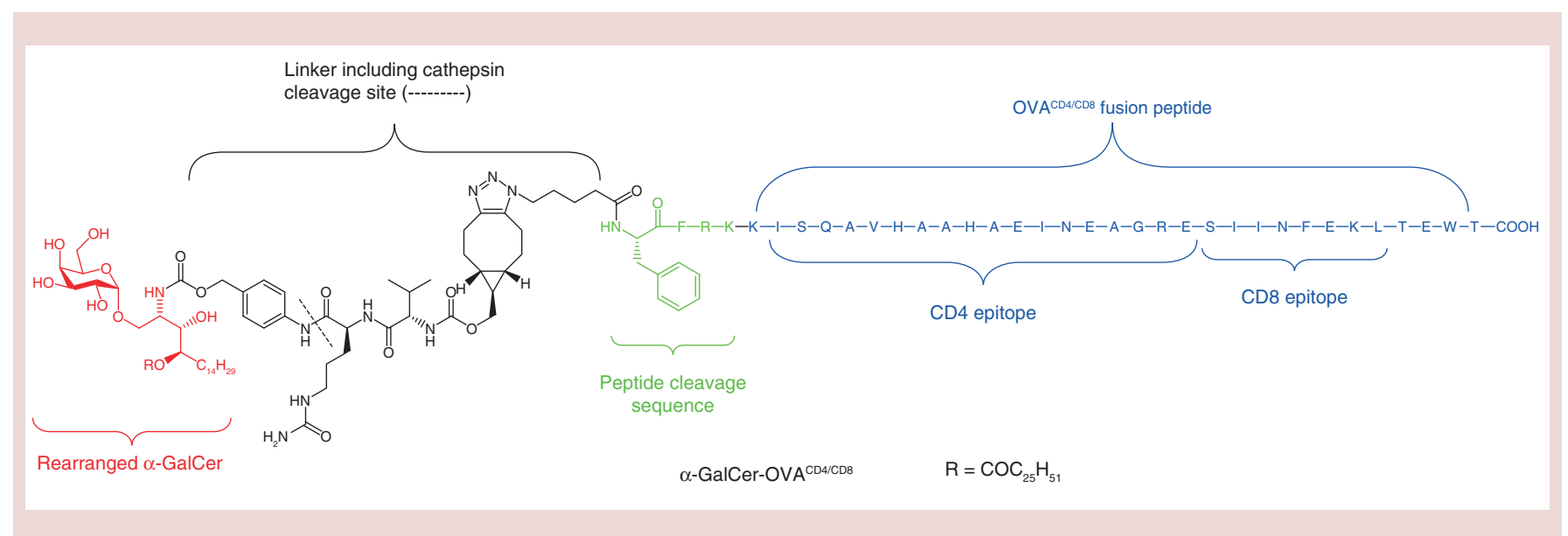

Figure 4. Synthetic antigen-specific $\alpha$-galactosylceramide vaccine. Chemical structure of synthetic vaccine, $\alpha-G a l C e r-O V A{ }^{C D 4 / C D 8}$. $\alpha$-GalCer: $\alpha$-Galactosylceramide; OVA: Ovalbumin.

peptides and adjuvant $\alpha$-GalCer to the same APC, this class of vaccine showed systemic antitumor efficacy in models of melanoma and lung cancer, and induced peptide-specific T-cell responses in human cells in vitro $[18,19]$.

Following intravenous administration, $\alpha$-GalCer-OVA ${ }^{\mathrm{CD} 4 / \mathrm{CD} 8}$ induced activation of splenic NKT cells (Supplementary Data Figure 1), and induced accumulation of $\mathrm{OVA}_{257-263}$-specific $\mathrm{CD} 8^{+} \mathrm{T}$ cells in blood after 7 days (Figure 5A). This T-cell response was NKT cell-dependent, as it was not observed in CD1d-deficient animals. Importantly, $\alpha$-GalCer-OVA ${ }^{\mathrm{CD}} 4 / \mathrm{CD} 8$ protected against intravenously administered E.G7-OVA, a derivative of EL4 that expresses OVA protein as a model of a TAA. This route of challenge otherwise results in formation of multiple extramedullary tumors outside the CNS (Figure 5B).

To assess activity against CNS lymphoma, $\alpha$-GalCer-OVA ${ }^{\mathrm{CD} 4 / \mathrm{CD} 8}$ was administered 7 days before intracranial E.G7-OVA challenge. Significant delays in development of lymphoma-related symptoms were observed (Figure 5C). Protection was also observed when the $\mathrm{CD} 4^{+}$T-cell epitope in the vaccine was modified to be inactive ( $\alpha$-GalCer$\mathrm{OVA}^{\mathrm{CD} 4 \mathrm{scr} / \mathrm{CD} 8}$ ), suggesting $\mathrm{CD} 8^{+} \mathrm{T}$ cells were primarily responsible for the antitumor activity (Figure 5D). In established lymphoma, $\alpha$-GalCer-OVA ${ }^{\mathrm{CD} 4 / \mathrm{CD} 8}$ alone failed to delay progression, but when combined with $\alpha-$ CD25, approximately $50 \%$ of mice remained symptom-free postchallenge (Figure $5 \mathrm{E}$ ), consistent with the cellular vaccine findings.

To explore the effector phase of the combined treatment strategy on intracranial E.G7-OVA tumors, immune infiltration into the whole brain was analyzed by flow cytometry 7 days after vaccination (Figure 6). To enable detection of leukocytes, and exclude tumor cells, CD45.2-expressing E.G7-OVA cells were engrafted into CD45.1 congenic hosts. The gating strategy to broadly detect lymphocytes $\left(\mathrm{CD} 45.1^{\text {hi }} \mathrm{CD} 11 \mathrm{~b}^{-}\right)$, macrophages $\left(\mathrm{CD} 45.1^{\text {hi }}\right.$ $\left.\mathrm{CD} 11 \mathrm{~b}^{\mathrm{hi}}\right)$ and microglia $\left(\mathrm{CD} 45.1^{\mathrm{int}} \mathrm{CD} 11 \mathrm{~b}^{\mathrm{int}}\right)$ is shown in Supplementary Figure 3. Lymphocytes were then phenotyped based on expression of CD3, CD4 and CD8, with $\mathrm{CD}^{+}{ }^{+}$Tregs defined based on expression of Foxp3.

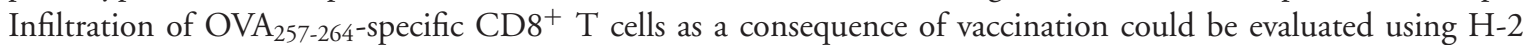
$\mathrm{K}^{\mathrm{b}} / \mathrm{OVA}_{257-264}$ pentamers. When expressed as fold-change in count relative to untreated controls, there was a trend toward increased numbers of leukocytes $\left(\mathrm{CD} 45.1^{+}\right.$cells) in the brains of mice treated with vaccine after Treg depletion with $\alpha$-CD25 (Figure 6A). This was largely attributable to increased T-cell numbers, rather than the myeloid cells assessed. Interestingly, the treatment did not induce an increase in brain-infitrating $\mathrm{CD}^{+} \mathrm{T}$ cells over controls, but did cause significant increases in $\mathrm{CD}^{+} \mathrm{T}$ cells, the majority of which were $\mathrm{OVA}_{257-264}$-specific (Figure 6B \& Supplementary Figure 4). Infiltrating T-cell subsets were quantified (Figure 6C).

\section{Discussion}

In clinical practice, vaccination might be offered after first-line therapy of systemic lymphoma to prevent late CNS relapse, or more challengingly, administered as a therapeutic strategy in patients with established CNS lymphoma. Here, we show that cellular and synthetic vaccines that engage the stimulatory activity of NKT cells to enhance T-cell responses can provide protection against CNS lymphoma development in vivo, but they need to be combined with a strategy to reduce Tregs to show activity against established CNS lymphoma. 
(A)

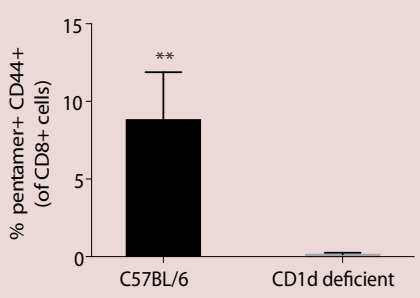

(C)

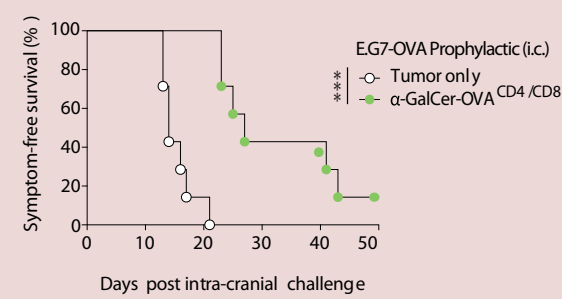

(E)

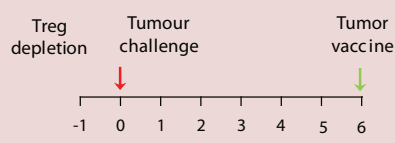

(B)
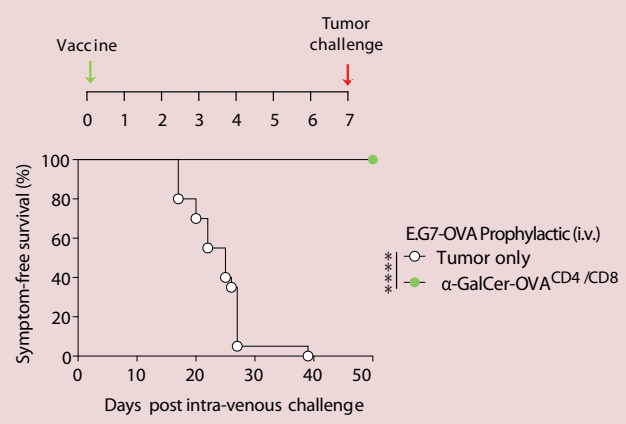

(D)
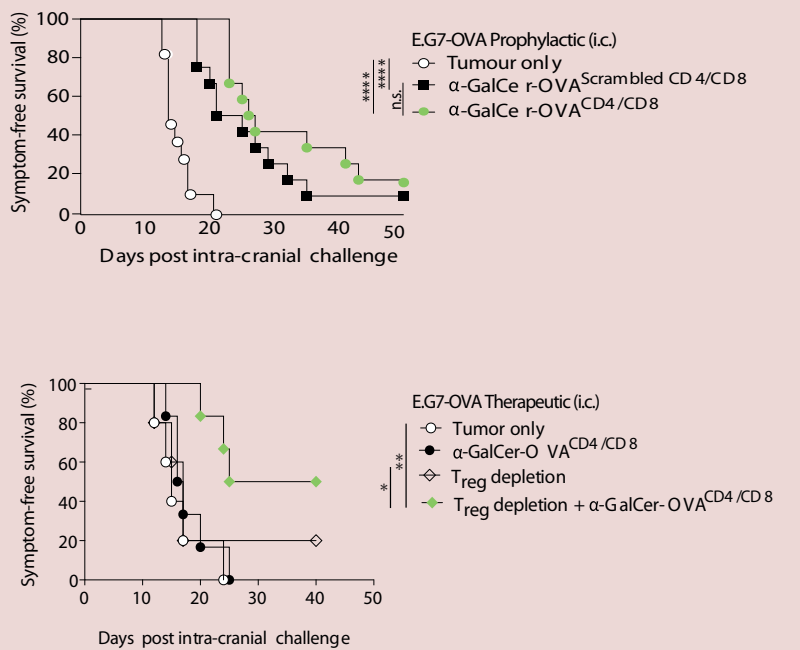

Figure 5. Synthetic antigen-specific $\alpha$-galactosylceramide vaccine combined with Treg depletion protects against systemic and CNS lymphoma. (A) C57BL/ 6 or CD1d-deficient mice vaccinated iv. with $\alpha$-GalCer-OVA ${ }^{\mathrm{CD} 4 / \mathrm{CD} 8}$ and blood assessed 7 days later for antigen-specific $\mathrm{CD}^{+}$T-cell expansion. Results are combination of two replicates, ( $n=5 /$ group), ** $p=0.001$. (B) Symptom-free survival curves for mice vaccinated iv. with either PBS (tumor only), or $\alpha$-GalCer-OVA ${ }^{\mathrm{CD} 4 / \mathrm{CD} 8}$ vaccine 7 days prior to i.v. injection of $1 \times 10^{6}$ E.G7-OVA cells ( $n=20$ /group). Results are combination of two independent replicate experiments. $* * * p<0.0001$. (C) Symptom-free survival curves for mice vaccinated 7 days prior to intracranial challenge with E.G7-OVA cells. Results are representative of two independent experiments: ( $n=7 /$ group), $* * * p<0.0001$. (D) Symptom-free survival curves for mice vaccinated with either PBS, $\alpha$-GalCer-OVA ${ }^{C D 4 / C D 8}$ vaccine or $\alpha$-GalCer-OVA ${ }^{C D 4 s c r / C D 8}$ vaccine (which has an altered CD4 ${ }^{+}$T-cell epitope) 7 days prior to intracranial challenge with E.G7-OVA cells ( $n=10 /$ group). Results are combination of two independent replicate experiments. (E) Symptom-free survival curves for mice challenged with intracranial E.G7-OVA treated with Treg depletion 1 day before tumor challenge, vaccination with $\alpha$-GalCer-OVA ${ }^{\mathrm{CD} 4 / \mathrm{CD} 8} 6$ days after tumor challenge, or both. Results representative of two independent experiments $(n=5-6 / 9$ roup). $* * p<0.01 ; * p<0.05$.

$\alpha$-GalCer: $\alpha$-Galactosylceramide; OVA: Ovalbumin; PBS: Phosphate-buffered saline.

Whole tumor cells loaded with $\alpha$-GalCer have been effectively used in models of systemic lymphoma [15,20], myeloid leukemia [29,30] and glioblastoma [27]. An earlier report of a live $\alpha$-GalCer loaded tumor cell vaccine showed that injected cells were killed by NKT cells, providing a reservoir of antigens for uptake by resident APCs [14]. However, we have previously induced antitumor activity using a CD1d-negative glioma cell line. It is therefore possible that the glycolipid incorporates into the lipid membranes of the injected cells for this transfer process. Although not tested here, a previous report has shown presence of $\alpha$-GalCer incorporated into CD1d-negative tumor cells [31]. We therefore anticipate that $\alpha$-GalCer can be transferred along with antigen from dying irradiated cells to resident APCs that in turn interact with NKT cells and drive the T-cell response.

As observed here, in general, these $\alpha$-GalCer-loaded cellular vaccines provided a level of prophylaxis against subsequent challenge with malignant cells, but when it came to treating established malignancies, alleviation from immunosuppresssion was undertaken in some cases. This took the form of de-bulking the tumor to reduce tumorinduced suppressor activities before vaccination, or Treg depletion, as conducted here. The protection afforded by $\alpha$-GalCer-pulsed whole tumor cells requires different effector cells in different models. In an E $\mu$-myc transgenic 

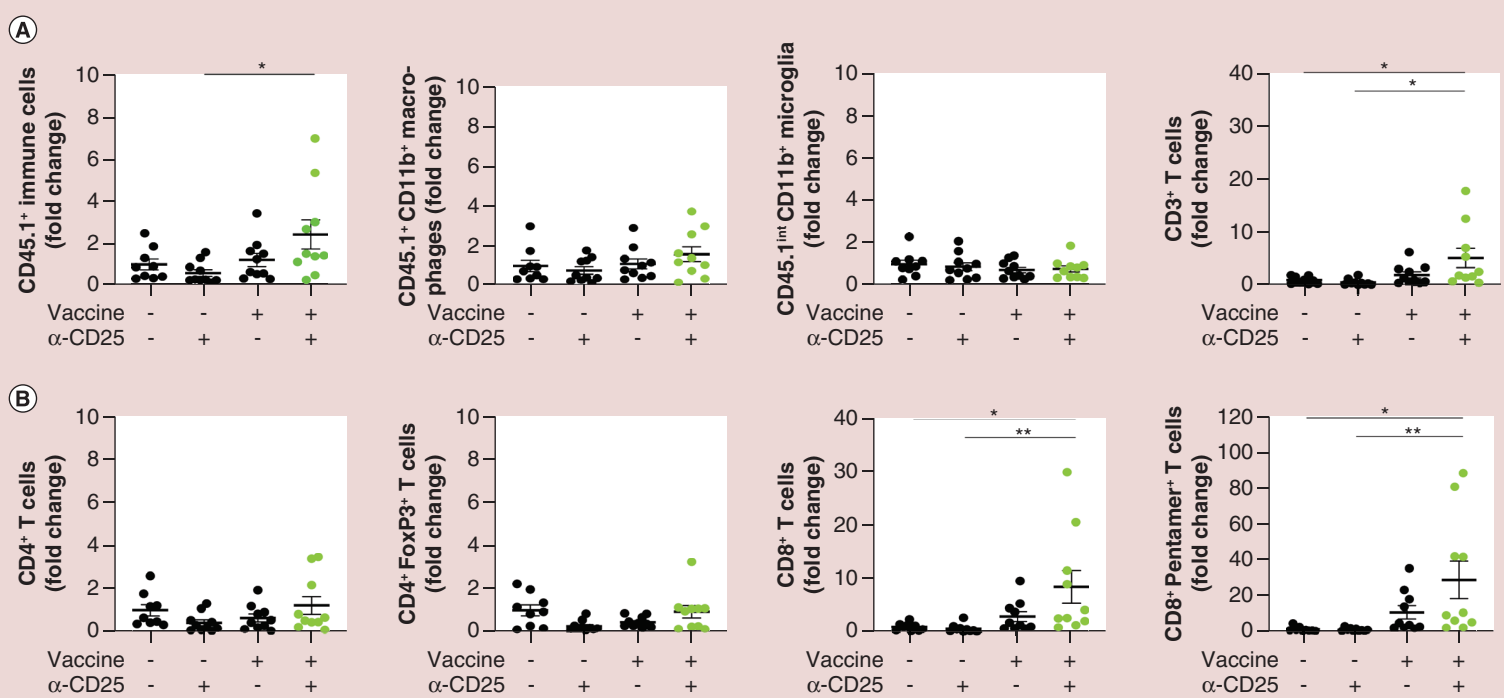

(C)
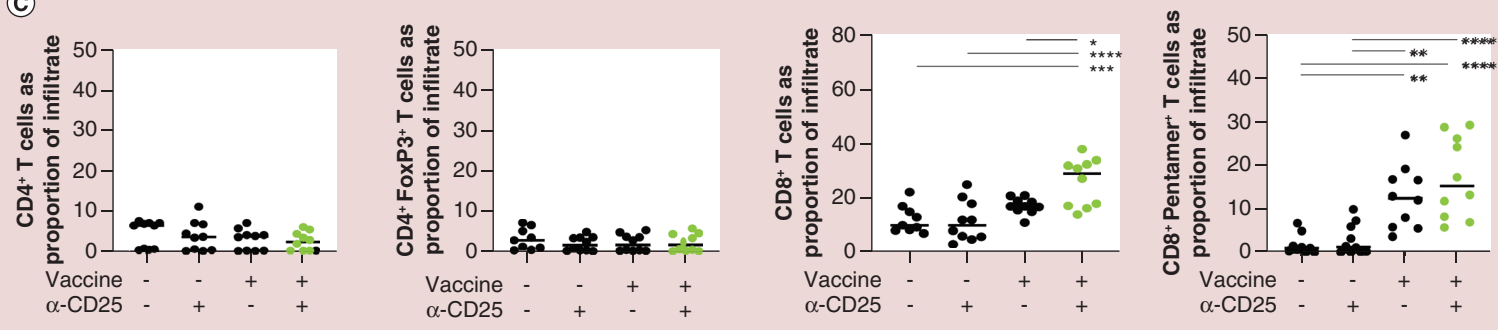

Figure 6. Therapeutic synthetic antigen-specific $\alpha$-galactosylceramide vaccine combined with Treg depletion is associated with accumulation of antigen-specific CD8 ${ }^{+} \mathrm{T}$ cells in the brain. CD45.1 congenic B6-SJ mice with intracranial E.G7-OVA tumors were treated with either $\alpha-C D 25$ for Treg depletion 6 days before vaccination, with the synthetic vaccine $\left(\alpha-G a l C e r-O V A{ }^{C D 4-C D 8}\right)$ or a combination of both. Whole brain immune infiltration was assessed by flow cytometry 7 days after vaccination. (A \& B) Quantification of total brain infiltrating CD45.1+ immune cells, macrophages $\left(\mathrm{CD} 45.1^{+} \mathrm{CD} 11 \mathrm{~b}^{+}\right)$, microglia $\left(\mathrm{CD} 45.1^{\text {int }} \mathrm{CD} 11 \mathrm{~b}^{+}\right)$and $\mathrm{T}_{\text {cells }}\left(\mathrm{CD} 3^{+}\right), \mathrm{CD}^{+} \mathrm{T}^{+}$cells, $\mathrm{CD} 4^{+}$ Foxp $^{+} \mathrm{T}$ cells, $\mathrm{CD} 8^{+} \mathrm{T}$ cells and $\mathrm{CD}^{+}$pentamer $^{+} \mathrm{T}$ cells. Fold-change in cell number for each animal over average cell number in the untreated group (PBS) is shown. (C) Quantification of infiltrating T-cell subsets as a proportion of total immune infiltrate. Combined data from two independent experiments ( $n=4 / 5$ mice/group). ${ }^{*} p<0.05 ; * * p<0.005 ; * * * p<0.0005$.

mouse model of spontaneous B-cell lymphoma, $\mathrm{CD} 8^{+} \mathrm{T}$ cells and NK cells were required [15], whereas both CD4 ${ }^{+}$ and $\mathrm{CD} 8^{+}$cells were required for systemic EL4 mouse B-cell lymphoma [29]. In the CNS setting, the glioblastoma vaccine was strictly dependent on $\mathrm{CD}^{+} \mathrm{T}$ cells, with very few infiltrating $\mathrm{CD} 8^{+} \mathrm{T}$ cells seen in the brain at all. Many models of CNS immune cell trafficking suggest a $\mathrm{CD}^{+}{ }^{+}$T-cell-dependent mechanism due to the preferential expression of integrins required for passage across the blood-brain barrier [32]. In a previous report of leukemia implanted intracranially, a delay was shown in the infiltration of $\mathrm{CD} 8^{+} \mathrm{T}$ cells, with a concurrent increase in the numbers of $\mathrm{CD}_{4}^{+} \mathrm{T}$ cells and Tregs [33]. In the current model, the cellular vaccine required both $\mathrm{CD}^{+}$and $\mathrm{CD}^{+}$cells for efficacy, perhaps reflecting this trafficking mechanism. However, in contrast, the synthetic vaccine did not appear to rely on this mechanism as there were no significant changes in $\mathrm{CD}^{+}{ }^{+} \mathrm{T}$-cell numbers in the brain in response to treatment, and a version of the vaccine that was incapable of stimulating TAA-specific CD4 ${ }^{+}$ $\mathrm{T}$ cells still showed efficacy. Thus, $\mathrm{CD} 8^{+} \mathrm{T}$ cells appear to be acting in isolation from $\mathrm{CD} 4^{+} \mathrm{T}$ cells in this model, although it is possible that the activation of NKT cells can compensate for some $\mathrm{CD} 4^{+}$T-cell functions. Certainly, when it comes to priming $\mathrm{CD}^{+} \mathrm{T}$ cells, NKT cells can compensate for lack of $\mathrm{CD} 4^{+} \mathrm{T}$-cell help, as strong responses to vaccines similar to $\alpha-G a l C e r-O V A{ }^{\mathrm{CD}} 4 / \mathrm{CD} 8$ can be mounted in MHC class II-deficient hosts, which lack conventional $\mathrm{CD} 4^{+} \mathrm{T}$ cells $[16,17]$. However, despite mounting strong $\mathrm{CD} 8^{+} \mathrm{T}$-cell responses, with evidence of antigen-specific $\mathrm{CD}^{+} \mathrm{T}$ cells reaching the brain, in general the synthetic vaccine was inferior to the cellular EL4 vaccine. This may yet reflect a need for eliciting sufficient suitable $\mathrm{CD}^{+}{ }^{+} \mathrm{T}$ cells to help target tumors in the CNS, or suggest that a broader response targeting more antigens is required. 
A subset of NKT cells express CD4 [34]. While the CD4-depleting antibody would have targeted these cells, we depleted $\mathrm{CD}^{+} \mathrm{T}$ cells 3-5 days after vaccination, whereas the licensing function afforded by NKT cells is required within $24 \mathrm{~h}$ of immune priming [35]. The impairment of efficacy following CD4 depletion therefore likely reflects loss of conventional CD4 ${ }^{+} \mathrm{T}$ cells, and not loss of NKT help. Antigen specificity of the effector cells induced with the cellular vaccines have not been determined in this study and it remains to be elucidated whether the $\mathrm{CD} 4^{+} \mathrm{T}$ cells involved in protection have cytotoxic ability or if they merely act to provide help for cytotoxic $\mathrm{CD} 8^{+} \mathrm{T}$-cell responses.

In this study, we combined therapeutic vaccination with Treg depletion to improve the antitumor response. The most obvious impact of combining the synthetic vaccine with Treg depletion was an overall increase in the proportion and number of T cells infiltrating the tumor, the majority of which were specific for the TAA targeted. More work is required to fully evaluate the mechanism for this combined activity, as the relief from immunosuppression could be important at priming or effector stages, or both. No specific agents for Treg depletion are in routine clinical use, but checkpoint inhibitors, which can alter Treg activity, are showing efficacy in the clinic [36,37]. Our own findings indicate that anti-CTLA- 4 can be effectively combined with an $\alpha$-GalCer-adjuvanted cellular vaccine in an orthotopic model of glioblastoma [38]; although not tested here, it is conceivable that checkpoint blockade could also be combined with vaccination to enhance efficacy in this CNS lymphoma model.

Vaccination with whole tumor cells adjuvanted with $\alpha$-GalCer is a feasible clinical strategy. Tumor biopsies can be used as a source of antigen for subsequent therapeutic vaccination [39], while the aggressive lymphomas at the highest risk of CNS relapse often present with bone marrow or peripheral blood involvement, providing other readily accessible sources of tumor cells for vaccine preparation. Numbers of NKT cells are lower in humans than in mice, but the NKT and CD1d axis has been shown to be intact in chronic lymphocytic leukemia, even after chemotherapy [40]. In clinical practice, whole tumor cell vaccination may be best employed in the postremission setting, when tumorassociated immunosuppression is relieved [41]. Clinical features allow identification of lymphoma patients at particularly high risk of CNS relapse [42], and one option would be to vaccinate these patients after completion of systemic therapy to reduce the risk of CNS recurrence.

Our findings suggest NKT cell-activating vaccines have the potential to prevent and treat CNS lymphoma. Vaccination could either be employed after first-line therapy of systemic lymphoma to prevent late CNS relapse, or administered in combination with Treg-depleting agents to treat patients with established CNS lymphoma. Ultimately, an off-the-shelf synthetic vaccine approach may be more feasible than whole tumor cell vaccination in clinical practice, provided immunogenic TAAs can be identified. Candidate antigens could include the L265P MYD88 mutation frequently observed in primary CNS lymphoma, for which antigenic epitopes have been described [43,44], or Epstein-Barr virus latency antigens commonly expressed by CNS lymphomas in immunocompromised individuals [45,46]. Alternatively, patient-specific TAAs identified by high-throughput tumor sequencing could be incorporated into personalized vaccines [47].

In summary, both cellular and synthetic vaccines that engage the stimulatory activity of NKT cells can protect against CNS lymphoma in vivo, and when combined with Treg depletion, are active against established CNS lymphoma.

\section{Conclusion}

NKT cell-activating vaccines enhance T-cell responses and have the potential to protect against CNS lymphoma development or prevent CNS relapse. To be effective against established CNS lymphoma, vaccines need to be combined with Treg suppression.

\section{Summary points}

- Whole tumor cell vaccines adjuvanted with $\alpha$-galactosylceramide ( $\alpha$-GalCer) provide protection against CNS lymphoma development via natural killer T (NKT) activation of $\mathrm{CD}^{+}$and $\mathrm{CD}^{+} \mathrm{T}$ cells.

- A synthetic vaccine comprising antigenic peptide conjugated to an $\alpha$-GalCer prodrug provides protection against CNS lymphoma development via NKT activation of $\mathrm{CD}^{+} \mathrm{T}$ cells.

- Cellular and synthetic NKT-activating vaccines require depletion of immunosuppressive Tregs to be effective against established CNS lymphoma. 


\section{Supplementary data}

To view the supplementary data that accompany this paper please visit the journal website at: www.futuremedicine.com/doi/sup pl/10.2217/imt-2019-0134

\section{Author contributions}

MV Berridge, C Grasso, IF Hermans and R Weinkove conceived the project. C Grasso, CS Field and C-W Tang collected data; C Grasso, CS Field, C-W Tang, IF Hermans and MV Berridge analyzed data; PM Ferguson analyzed pathology of tumors; GF Painter and IF Hermans designed synthetic vaccine; BJ Compton and RJ Anderson manufactured synthetic vaccine; C Grasso, IF Hermans and $\mathrm{R}$ Weinkove wrote the manuscript. All the authors read and approved the final manuscript.

\section{Acknowledgments}

The authors wish to acknowledge LE McVeigh for tissue collection.

\section{Financial \& competing interests disclosure}

This study was supported by Cure Kids, New Zealand (grant CHRF 9499); The Cancer Society of New Zealand Wellington Division; Ministry of Business Innovation and Employment (grant RTV1603); Genesis Oncology Trust (grant GOT-1548-RPG) and the Health Research Council of New Zealand (grant HRC 14/500). CS Field was supported by a post-graduate scholarship from the Genesis Oncology Trust (GOT-1240-PGS). GF Painter, R Weinkove and IF Hermans were supported by the Thompson Family Foundation. IF Hermans and GF Painter have a proprietary interest in the synthetic vaccines described and are members of the management team of Avalia Immunotherapies. R Weinkove has acted as a scientific advisory board member for Avalia Immunotherapies. The authors have no other relevant affiliations or financial involvement with any organization or entity with a financial interest in or financial conflict with the subject matter or materials discussed in the manuscript apart from those disclosed.

No writing assistance was utilized in the production of this manuscript.

\section{Ethical conduct of research}

All experiments were approved by the Victoria University Animal Ethics Committee and performed according to institutional guidelines.

\section{Open access}

This work is licensed under the Attribution-NonCommercial-NoDerivatives 4.0 Unported License. To view a copy of this license, visit http://creativecommons.org/licenses/by-nc-nd/4.0/

\section{References}

1. Shiels MS, Pfeiffer RM, Besson C et al. Trends in primary central nervous system lymphoma incidence and survival in the U.S. Br. J. Haematol. 174(3), 417-424 (2016).

2. Grommes $\mathrm{C}$, Pastore A, Palaskas $\mathrm{N}$ et al. Ibrutinib unmasks critical role of bruton tyrosine kinase in primary CNS lymphoma. Cancer Discov 7(9), 1018-1029 (2017).

3. Hickey WF, Hsu BL, Kimura H. T-lymphocyte entry into the central nervous system. J. Neurosci. Res. 28(2), 254-260 (1991).

4. Marron TU, Ronner L, Martin PE, Flowers CR, Brody JD. Vaccine strategies for the treatment of lymphoma: preclinical progress and clinical trial update. Immunotherapy 8(11), 1335-1346 (2016).

5. Sugita Y, Furuta T, Ohshima K et al. The perivascular microenvironment in Epstein-Barr virus positive primary central nervous system lymphoma: the role of programmed cell death 1 and programmed cell death ligand 1. Neuropathology 38(2), 125-134 (2017).

6. Gonzalez-Aseguinolaza G, Van Kaer L, Bergmann CC et al. Natural killer T cell ligand alpha-galactosylceramide enhances protective immunity induced by malaria vaccines. J. Exp. Med. 195(5), 617-624 (2002).

7. Taraban VY, Martin S, Attfield KE et al. Invariant NKT cells promote CD8+ cytotoxic $\mathrm{T}$ cell responses by inducing CD70 expression on dendritic cells. J. Immunol. 180(7), 4615-4620 (2008).

8. Fujii S, Liu K, Smith C, Bonito AJ, Steinman RM. The linkage of innate to adaptive immunity via maturing dendritic cells in vivo requires CD40 ligation in addition to antigen presentation and CD80/86 costimulation. J. Exp. Med. 199(12), 1607-1618 (2004).

9. Kawano T, Cui J, Koezuka Y et al. CD1d-restricted and TCR-mediated activation of valpha14 NKT cells by glycosylceramides. Science 278(5343), 1626-1629 (1997).

10. Fujii S, Shimizu K, Smith C, Bonifaz L, Steinman RM. Activation of natural killer T cells by alpha-galactosylceramide rapidly induces the full maturation of dendritic cells in vivo and thereby acts as an adjuvant for combined CD4 and CD8 T cell immunity to a coadministered protein. J. Exp. Med. 198(2), 267-279 (2003). 
11. Hermans IF, Silk JD, Gileadi U et al. NKT cells enhance CD4+ and CD8+ T cell responses to soluble antigen in vivo through direct interaction with dendritic cells. J. Immunol. 171(10), 5140-5147 (2003).

12. Cerundolo V, Silk JD, Masri SH, Salio M. Harnessing invariant NKT cells in vaccination strategies. Nat. Rev. Immunol. 9(1), 28-38 (2009).

13. Speir M, Hermans IF, Weinkove R. Engaging natural killer T cells as 'universal helpers' for vaccination. Drugs 77(1), 1-15 (2017).

14. Hunn MK, Farrand KJ, Broadley KW et al. Vaccination with irradiated tumor cells pulsed with an adjuvant that stimulates NKT cells is an effective treatment for glioma. Clin. Cancer Res. 18(23), 6446-6459 (2012).

15. Mattarollo SR, West AC, Steegh K et al. NKT cell adjuvant-based tumor vaccine for treatment of myc oncogene-driven mouse B-cell lymphoma. Blood 120(15), 3019-3029 (2012).

16. Anderson RJ, Tang CW, Daniels NJ et al. A self-adjuvanting vaccine induces cytotoxic T lymphocytes that suppress allergy. Nat. Chem. Biol. 10(11), 943-949 (2014).

17. Cavallari M, Stallforth P, Kalinichenko A et al. A semisynthetic carbohydrate-lipid vaccine that protects against S. pneumoniae in mice. Nat. Chem. Biol. 10(11), 950-956 (2014).

18. Anderson RJ, Compton BJ, Tang CW et al. NKT cell-dependent glycolipid-peptide vaccines with potent anti-tumour activity. Chem. Sci. 6(9), 5120-5127 (2015).

19. Speir M, Authier-Hall A, Brooks CR et al. Glycolipid-peptide conjugate vaccines enhance CD8(+) T cell responses against human viral proteins. Sci. Rep. 7(1), 14273 (2017).

20. Chung Y, Qin H, Kang CY, Kim S, Kwak LW, Dong C. An NKT-mediated autologous vaccine generates CD4 T-cell dependent potent antilymphoma immunity. Blood 110(6), 2013-2019 (2007).

21. Lee A, Farrand KJ, Dickgreber N et al. Novel synthesis of alpha-galactosyl-ceramides and confirmation of their powerful NKT cell agonist activity. Carbohyd. Res. 341(17), 2785-2798 (2006).

22. Giaccone G, Punt CJ, Ando Y et al. A Phase I study of the natural killer T-cell ligand alpha-galactosylceramide (KRN7000) in patients with solid tumors. Clin. Cancer Res. 8(12), 3702-3709 (2002).

23. Feng H, Zeng Y, Graner MW, Katsanis E. Stressed apoptotic tumor cells stimulate dendritic cells and induce specific cytotoxic T cells. Blood 100(12), 4108-4115 (2002).

24. Anderson RJ, Li J, Kedzierski L et al. Augmenting influenza-specific $\mathrm{T}$ cell memory generation with a natural killer $\mathrm{T}$ cell-dependent glycolipid-peptide vaccine. ACS Chem. Biol. 12(11), 2898-2905 (2017).

25. Rosenblatt J, Vasir B, Uhl L et al. Vaccination with dendritic cell/tumor fusion cells results in cellular and humoral antitumor immune responses in patients with multiple myeloma. Blood 117(2), 393-402 (2011).

26. Burkhardt UE, Hainz U, Stevenson $\mathrm{K}$ et al. Autologous CLL cell vaccination early after transplant induces leukemia-specific $\mathrm{T}$ cells. J. Clin. Invest. 123(9), 3756-3765 (2013).

27. Hunn MK, Farrand KJ, Broadley KW et al. Vaccination with irradiated tumor cells pulsed with an adjuvant that stimulates NKT cells is an effective treatment for glioma. Clin. Cancer Res. 18(23), 6446-6459 (2012).

28. Guo C, Manjili MH, Subjeck JR, Sarkar D, Fisher PB, Wang XY. Therapeutic cancer vaccines: past, present, and future. Adv. Cancer Res. 119, 421-475 (2013)

29. Shimizu K, Kurosawa Y, Taniguchi M, Steinman RM, Fujii S. Cross-presentation of glycolipid from tumor cells loaded with alpha-galactosylceramide leads to potent and long-lived T cell mediated immunity via dendritic cells. J. Exp. Med. 204(11), 2641-2653 (2007).

30. Gibbins JD, Ancelet LR, Weinkove R et al. An autologous leukemia cell vaccine prevents murine acute leukemia relapse after cytarabine treatment. Blood 124(19), 2953-2963 (2014).

31. Shimizu K, Goto A, Fukui M, Taniguchi M, Fujii S. Tumor cells loaded with alpha-galactosylceramide induce innate NKT and NK cell-dependent resistance to tumor implantation in mice. J. Immunol. 178(5), 2853-2861 (2007).

32. Engelhardt B. Molecular mechanisms involved in T cell migration across the blood-brain barrier. J. Neural Transm. 113(4), 477-485 (2006).

33. Donnou S, Galand C, Daussy C et al. Immune adaptive microenvironment profiles in intracerebral and intrasplenic lymphomas share common characteristics. Clin. Exp. Immunol. 165(3), 329-337 (2011).

34. Lantz $\mathrm{O}$, Bendelac A. An invariant $\mathrm{T}$ cell receptor alpha chain is used by a unique subset of major histocompatibility complex class I-specific CD4+ and CD4-8- T cells in mice and humans. J. Exp. Med. 180(3), 1097-1106 (1994).

35. Kitamura H, Iwakabe K, Yahata $\mathrm{T}$ et al. The natural killer T (NKT) cell ligand alpha-galactosylceramide demonstrates its immunopotentiating effect by inducing interleukin (IL)-12 production by dendritic cells and IL-12 receptor expression on NKT cells. J. Exp. Med. 189(7), 1121-1128 (1999).

36. Nayak L, Iwamoto FM, Lacasce A et al. PD-1 blockade with nivolumab in relapsed/refractory primary central nervous system and testicular lymphoma. Blood 129(23), 3071-3073 (2017). 
37. Terziev D, Hutter B, Klink B et al. Nivolumab maintenance after salvage autologous stem cell transplantation results in long-term remission in multiple relapsed primary CNS lymphoma. Eur. J. Haematol. 101(1), 115-118 (2018).

38. Field CS, Hunn MK, Ferguson PM, Ruedl C, Ancelet LR, Hermans IF. Blocking CTLA-4 while priming with a whole cell vaccine reshapes the oligoclonal T cell infiltrate and eradicates tumors in an orthotopic glioma model. Oncoimmunology 7(1), e1376154 (2017).

39. Hunn MK, Bauer E, Wood CE et al. Dendritic cell vaccination combined with temozolomide retreatment: results of a Phase I trial in patients with recurrent glioblastoma multiforme. J. Neurooncol. 121(2), 319-329 (2015).

40. Weinkove R, Brooks CR, Carter JM, Hermans IF, Ronchese F. Functional invariant natural killer T-cell and CD1d axis in chronic lymphocytic leukemia: implications for immunotherapy. Haematologica 98(3), 376-384 (2013).

41. Weinkove R, Ancelet LR, Gibbins JD, Hermans IF. An adjuvanted whole cell vaccine as post-remission immunotherapy for acute leukemia. Oncoimmunology 4(4), e995568 (2015).

42. Boehme $\mathrm{V}$, Zeynalova $\mathrm{S}$, Kloess $\mathrm{M}$ et al. Incidence and risk factors of central nervous system recurrence in aggressive lymphomaa - a survey of 1693 patients treated in protocols of the German High-Grade Non-Hodgkin's Lymphoma Study Group (DSHNHL). Ann. Oncol. 18(1), 149-157 (2007).

43. Braggio E, Van Wier S, Ojha J et al. Genome-wide analysis uncovers novel recurrent alterations in primary central nervous system lymphomas. Clin. Cancer Res. 21(17), 3986-3994 (2015).

44. Nelde A, Walz JS, Kowalewski DJ et al. HLA class I-restricted MYD88 L265P-derived peptides as specific targets for lymphoma immunotherapy. Oncoimmunology 6(3), e1219825 (2017).

45. Bollard CM, Gottschalk $S$, Torrano $\mathrm{V}$ et al. Sustained complete responses in patients with lymphoma receiving autologous cytotoxic $\mathrm{T}$ lymphocytes targeting Epstein-Barr virus latent membrane proteins. J. Clin. Oncol. 32(8), 798-808 (2014).

46. Tellam J, Connolly G, Green KJ et al. Endogenous presentation of CD8+ T cell epitopes from Epstein-Barr virus-encoded nuclear antigen 1. J. Exp. Med. 199(10), 1421-1431 (2004).

47. Sahin U, Derhovanessian E, Miller M et al. Personalized RNA mutanome vaccines mobilize poly-specific therapeutic immunity against cancer. Nature 547(7662), 222-226 (2017). 